\title{
Parámetros de mayor riesgo ambiental provenientes de efluentes líquidos en el Subsector Hidrocarburos
}

Higher environmental risk parameters from liquid effluents in the hydrocarbons subsector

Recibido: mayo 15 de 2019 | Revisado: junio 20 de 2019 | Aceptado: julio 11 de 2019

\author{
Katherine CAMACho-Zorogastúa ${ }^{I}$ \\ Víctor Gallo-Ramos ${ }^{2}$
}

\begin{abstract}
Resumen
Esta investigación tuvo como objetivo conocer los parámetros provenientes de efluentes líquidos que pueden generar mayor riesgo al ambiente y salud de las personas, mediante el análisis crítico-científico contenido en la literatura de fuentes bibliográficas internacionales. Para lo cual se consideraron criterios técnico-científicos adoptados por tres (3) agencias internacionales de los Estados Unidos y Europa, tales como Agency for toxic Substances \& Disease Registry (ATSDR), Institute for health and Consumer Protection (IHCP) y United States Environmental Protection Agency (EPA). Se concluyó que el cadmio, plomo y mercurio (en ese orden) son los que pueden generar mayor impacto al ambiente y a la salud de las personas. Tales criterios están en función de sus propiedades carcinogénicas, bioacumulativas, biomanificación, efectos tóxicos y vida media biológica.
\end{abstract}

Palabras clave: Parámetros de mayor riesgo ambiental, efluentes líquidos, Subsector Hidrocarburos

\begin{abstract}
The main objective of this research was to know the parameters coming from liquid effluents that pose a greater risk to the environment and health of people, through critical - scientific analysis, contained in the literature of international bibliographic sources. An empirical, theoretical and deductive research of non-experimental design was carried out, for which the technical-scientific criteria adopted by 3 international agencies of the United States and Europe, such as Agency for toxic Substances and Disease Registry (ATSDR), Institute, were considered for Health and Consumer Protection (IHCP) and United States Environmental Protection Agency (EPA). It was concluded, that Cadmiun, Lead and Mercury (in that order) can generate the greatest impact on the environment and health of people. Such parameters were based on their cancinogenic, bioaccumulative, biomagnification, toxic effects and biological half -life.
\end{abstract}

Key words: Greater environmental risk parameters, liquid effluents, Subsector Hydrocarbons katheryne.camachoz@gmail.com

2 Universidad Nacional Federico Villarreal

\footnotetext{
(C) Los autores. Este artículo es publicado por la Revista Campus de la Facultad de Ingeniería y Arquitectura de la Universidad de San Martín de Porres. Este artículo se distribuye en los términos de la Licencia Creative Commons Atribución No-comercial - Compartir-Igual 4.0 Internacional (https://creativecommons.org/licenses/ CC-BY), que permite el uso no comercial, distribución y reproducción en cualquier medio siempre que la obra original sea debidamente citada. Para uso comercial contactar a: revistacampus@usmp.pe.
} 


\section{Introducción}

El Perú viene desarrollando progresivamente la gestión de recursos hídricos, protección de la salud, tecnología y productividad con la finalidad de alcanzar un enfoque sistémico al tratamiento y adecuación de factores ambientales como son el uso eficiente del agua y la generación de efluentes líquidos generados por actividades productivas y poblacionales (Autoridad Nacional del Agua - ANA, 2016, págs. 5-7).

A nivel nacional, dentro de las actividades productivas se encuentra el Subsector Hidrocarburos, en cuyos procesos se generan efluentes líquidos domésticos e industriales (Autoridad Nacional del Agua - ANA, 2016, pág. 8) que en su mayoría o bien son tratados de forma inadecuada o simplemente no cuentan con un tratamiento previo antes de ser descargados al ambiente, poniendo en riesgo la salud de las personas, biodiversidad, refugios de fauna silvestre y sus servicios ambientales; y, alteran la composición natural (original) de los cuerpos receptores a los que estos efluentes son vertidos (López, 2011, pág. 1). Si bien los operadores de este subsector han mejorado las técnicas para el tratamiento de sus efluentes líquidos (Universidad Nacional Agraria La Molina - UNALM, 2017), aún existe la problemática de la contaminación de los componentes ambientales, sobre todo en cuerpos hídricos (quebradas, ríos, lagos, lagunas, aguas subterráneas, mar, etc.) y en una menor proporción en los suelos (Arévalo Aranda, 2016, págs. 1-6).
Laafectación hacia los cuerpos receptores mencionados generada por el inadecuado tratamiento y/o vertimiento (sin previo tratamiento), se debe a la concentración de los contaminantes de estos efluentes. Los efluentes domésticos provenientes de los campamentos base y volantes, oficinas administrativas, uso personal, cocina, etc. de los proyectos del Subsector Hidrocarburos están conformados por una alta carga de materia orgánica y patógenos $(\mathrm{DBO}$, DQO, Coliformes Totales, Coliformes Fecales, fósforo, nitrógeno, etc.) (Bedoya Pérez, Ardilla Arias, \& Reyes Calle, 2014, págs. 275-283); mientras que los efluentes industriales poseen una alta concentración de metales pesados, hidrocarburos totales de petróleo (TPH), aceites y grasas, sólidos suspendidos totales, entre otros (Fernández Gordón, 2013, págs. 6-8).

Es importante mencionar que, dichos contaminantes no solo afectan a los cuerpos receptores abióticos (agua, suelos) sino también a los bióticos (organismos vivos que habitan en ellos), alterando su funcionalidad en el ecosistema, desde productores hasta consumidores dentro de la cadena trófica (Landis \& Ming-Ho, 2003, págs. 221-222).

\section{Cadena de valor}

Las actividades que comprenden la cadena de valor en el Subsector Hidrocarburos se dividen en dos: (i) upstream y, (ii) downstream. Upstream es el proceso de encontrar y extraer petróleo y/o gas del suelo, y comprende las etapas de exploración (prospección sísmica y perforación exploratoria) y explotación (producción ${ }^{1}$ ). Downstream,

1 Proceso en el que se extraen los hidrocarburos (petróleo y gas) desde la capa de roca hasta la superficie. Se utilizan dos mecanismos, a través de: (i) válvulas llamadas Árbol de Navidad (cuando los hidrocarburos fluyen a la superficie por sí solos); y, (ii) una máquina Balancín (cuando el hidrocarburo necesita ayuda para subir a la superficie). 
abarca la refinación ${ }^{2}$, transporte ${ }^{3}$ y comercialización ${ }^{4} \quad$ (Agencia Nacional de Hidrocarburos - ANH, 2016). (Figura 1).

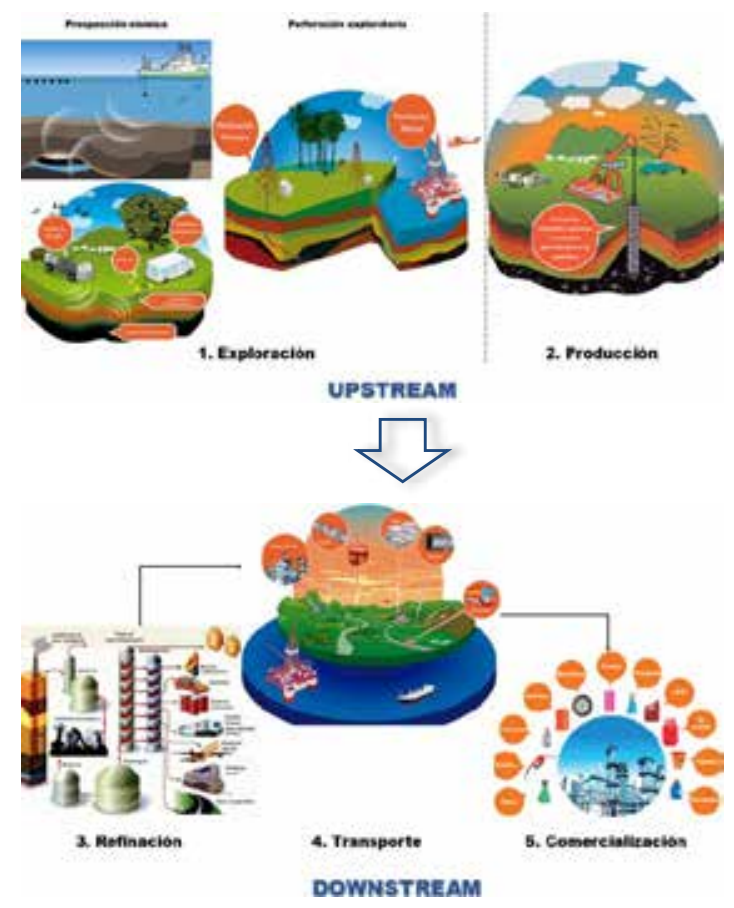

Figura 1. Upstream y Downstream

Fuente: Adaptado de (Agencia Nacional de Hidrocarburos - ANH, 2016).

Durante el desarrollo de estas actividades se generan, entre otros, efluentes líquidos (domésticos e industriales) que contienen una gran diversidad de compuestos químicos que son vertidos al ambiente y en la mayoría de los casos se les da un tratamiento previo antes de su disposición final (Orozco Barrenetxea, Perez Serrano, \& Gonzalez Delgado, 2004, pág. 195). Sin embargo, este tratamiento, en todos los casos no resulta ser idóneo o en su defecto no es cumplido a cabalidad por los operadores, según lo establecido en sus instrumentos de gestión ambiental aprobados por la autoridad certificadora y la normativa ambiental vigente (Savia Perú S.A., 2010).

\section{Efluentes líquidos}

Los efluentes líquidos generados por el desarrollo de actividades antropogénicas son aquellos que se caracterizan por tener altas concentraciones de materia orgánica, sólidos suspendidos, nutrientes, patógenos, metales pesados, etc. y que por su contenido requieren de un tratamiento previo y permisos ambientales antes de su vertimiento (López, 2011, pág. 1). En términos generales existen dos (2) tipos: (i) domésticos; e, (ii) industriales. Los domésticos provienen de los servicios higiénicosobaños portátiles, cocina, ducha, entre otros similares, que constituyen potenciales contaminantes bacteriológicos desencadenantes de enfermedades (López, 2011); mientras que los industriales, provienen de los procesos desarrollados en las diferentes etapas de la cadena de valor (Decreto Supremo No 039-2014-EM), de acuerdo con lo siguiente:

\section{Prospección sísmica}

(i) Marina: Provenientes de las aguas de sentina y lastre; (ii) terrestre: se generan principalmente efluentes domésticos (Orozco Barrenetxea, Perez Serrano, \& Gonzalez Delgado, 2004, pág. 195).

\section{Perforación exploratoria}

Provienen del uso de sustancias químicas (aditivos de los lodos) que reaccionan con los cortes de perforación (Ortiz Valbuena, 2016, pág. 16). Asimismo, las aguas de extracción son líquidos que salen del subsuelo junto con el petróleo y se componen esencialmente de agua, pero pueden contener otros elementos tales como hidrocarburos, metales disueltos, sólidos suspendidos y algunas sustancias

\footnotetext{
2 Consiste en transformar el petróleo sometiéndolo a temperaturas altas, que alcanzan $\operatorname{los} 400^{\circ} \mathrm{C}$, para obtener productos derivados.

3 A través de oleoductos, carrotanques y buques (petróleo) y gasoductos (gas).
}

4 Actividades comerciales, para colocar los productos a disposición de los usuarios. Se utilizan distribuidores mayoristas o minoristas. 
químicas que caen al pozo durante las operaciones (Paumier Verlayn \& Nuñez, 2007, págs. 111-112).

\section{Producción}

Proceden del proceso de perforación de pozos de desarrollo, debido al uso de sustancias químicas para romper las emulsiones en la fase de producción y transporte desde las plataformas hacia las baterías de producción; así como también del mantenimiento de tanques de almacenamiento, tuberías y otros (Cornejo Cabellos, 1995, págs. 12-13).

\section{Refinación}

Resultan de efluentes líquidos que convergen al desagüe aceitoso del área de procesos, salmueras producto del tratamiento de crudo en desaladoras de las unidades de destilación (arrastran sales, sólidos, sedimentos, metales y crudo emulsionado) y de los filtros de sal (productos intermedios, kerosene, diésel, etc.), aguas ácidas del condensado (contiene cloruros, amoniaco, etc.), agua de refrigeración (enfriamiento de área de procesos), desagüe de productos químicos resultantes de planta de servicios industriales (constituido por ácido clorhídrico gastado y soda cáustica), entre otros (PETROPERÚ, 1995).

\section{Transporte}

Derivan del mantenimiento de tanques de almacenamiento y alivio, tuberías, ductos (y accesorios), pozas API y otros (Cornejo Cabellos, 1995, págs. 23-26).

\section{Comercialización}

Provienen de la limpieza de zonas de derrames de combustible (Cárdenas Saldaña, 2011, págs. 64,73-74).

Cabe precisar que, los efluentes domésticos en todas las etapas provienen de los campamentos (volantes y base), actividades de aseo y cocina, oficinas administrativas y etc.

\section{Parámetros de efluentes líquidos}

Mediante Decreto Supremo N 037 2008-PCM se establecen los Límites Máximos Permisibles (en adelante, LMP) de efluentes líquidos en el Subsector Hidrocarburos, cuyo detalle se muestra en la Tabla 1.

Tabla 1

\section{LMP de efluentes liquidos}

\begin{tabular}{|c|c|}
\hline Parámetro regulado & $\begin{array}{c}\text { LMP para } \\
\text { concentraciones } \\
\text { en Cualquier } \\
\text { momento }(\mathrm{mg} / \mathrm{L})\end{array}$ \\
\hline $\begin{array}{c}\text { Hidrocarburos Totales de Petróleo } \\
\text { (TPH) }\end{array}$ & 20 \\
\hline Cloruro & $\begin{array}{l}500 \text { (ríos, lagos y } \\
\text { embalses) } \\
2000 \text { (estuarios) }\end{array}$ \\
\hline Cromo hexavalente $\left(\mathrm{Cr}^{+6}\right)$ & 0,1 \\
\hline Cromo Total $\left(\mathrm{Cr}_{\mathrm{t}}\right)$ & 0,5 \\
\hline Mercurio $(\mathrm{Hg})$ & 0,02 \\
\hline Cadmio (Cd) & 0,1 \\
\hline Arsénico (As) & 0,2 \\
\hline $\begin{array}{l}\text { Fenoles para efluentes de refinerías } \\
\text { FCC }\end{array}$ & 0,5 \\
\hline
\end{tabular}

\begin{tabular}{lc}
\hline $\begin{array}{l}\text { Sulfuros para efluentes de refinerías } \\
\text { FCC }\end{array}$ & 1 \\
\hline $\begin{array}{l}\text { Demanda bioquímica de Oxígeno } \\
\text { (DBO) }\end{array}$ & 50 \\
\hline $\begin{array}{l}\text { Demanda química de Oxígeno } \\
\text { (DQO) }\end{array}$ & 250 \\
\hline Cloro Residual & 0,2 \\
\hline Nitrógeno amoniacal & 40 \\
\hline Coliformes totales $(\mathrm{NMP} / 100 \mathrm{~mL})$ & $<1000$ \\
\hline Coliformes Fecales $(\mathrm{NMP} / 100 \mathrm{~mL})$ & $<400$ \\
\hline Fósforo $(\mathrm{P})$ & 2 \\
\hline Bario $(\mathrm{Ba})$ & 5 \\
\hline pH & 6 a 9 \\
\hline Aceites y grasas & 20 \\
\hline Plomo $(\mathrm{Pb})$ & 0.1 \\
\hline Incremento de Temperatura ${ }^{\mathrm{a}}$ & $<3^{\circ} \mathrm{C}$ \\
\hline
\end{tabular}

(a) Es el incremento respecto a la temperatura ambiental del cuerpo receptor medida a 100 metros de diámetro del punto de vertido. Fuente: (Decreto Supremo $N^{\circ}$ 037-2008-PCM). 


\section{Hidrocarburos Totales (TPH)}

El término TPH se usa para describir a un grupo extenso de diversas sustancias químicas derivadas originalmente del petróleo crudo (Estrella Moreira \& Guevara, 2011, págs. 1-3). Se les llama hidrocarburos porque casi todos los componentes están formados de hidrógeno y carbono. Algunos TPH son líquidos incoloros o de color claro que se evaporan fácilmente, mientras que otros son líquidos espesos de color oscuro o semisólidos que no se evaporan, tienen un olor característico a gasolina, kerosén o aceite (ATSDR, 1999, pág. 2).

\section{Potencial de hidrógeno $(\mathrm{pH})$}

Es una medida de concentración del ion hidrógeno en el agua, siendo importante su determinación por la influencia que tiene en el desarrollo de la vida acuática y se expresa la concentración de este ion como $\mathrm{pH}$, que se define como el logaritmo decimal cambiado de signo de la concentración de ion hidrógeno (Programa de Desarrollo Institucional Ambiental, 1999, pág. 82). Su medición es considerada un elemento de juicio fundamental en la caracterización $y$ muestras de suelo debido a que afecta a la disponibilidad de nutrientes y la actividad microbiana (Arraz Gonzales, 2011, pág. 175).

\section{Aceites y grasas}

Lo constituyen las partículas de grasas y/o las películas de aceites o líquidos (hidrocarburos con metales pesados $y$ PCB) que pueden dispersarse sobre una extensa superficie, que otorgan un aspecto estético desagradable y disminuyen el paso de la luz hacia la fase acuosa (Programa de Desarrollo Institucional Ambiental, 1999, pág. 82). Se considera cualquier material recuperado de la muestra acidificada, como una sustancia soluble en éter de petróleo y no votalizables durante el ensayo (incluyendo otros materiales extractables por el solvente) (Aguinaga, 1996, págs. 06521-1).

\section{Temperatura $\left({ }^{\circ} \mathrm{C}\right)$}

La temperatura del agua tiene una gran importancia en el desarrollo de los diversos procesos que en ella se realizan, de forma que su aumento modifica la solubilidad de las sustancias, incrementando la de los sólidos disueltos y disminuyendo la de los gases. La actividad biológica se duplica cada $10 \mathrm{C}^{\circ}$ (ley del $Q_{10}$ ), aunque superado un cierto valor característico de cada especie viva, tiene efectos letales para los organismos. Un aumento anormal (por causas no climáticas), suele tener origen en el vertido de aguas utilizadas en procesos industriales de intercambio de calor (Jimenez Aznar, 2000, pág. 3).

\section{Materiales y Método}

\section{Materiales}

Para la presente investigación se utilizó material bibliográfico como apoyo científico y técnico de instituciones reconocidas a nivel internacional, basadas en políticas europeas y americanas tales como:

- Agency for Toxic Substances \& Disease Registry (ATSDR).

- Institute for Health and Consumer Protection (IHCP).

- C. United States Environmental Protection Agency (EPA). 


\section{Método}

El objetivo aquí es conocer los parámetros provenientes de los efluentes líquidos que poseen mayor riesgo para el ambiente y salud de las personas, mediante el análisis crítico-científico contenido en la literatura de fuentes bibliográficas internacionales, debido a que en la actualidad se cuenta con poca información de carácter técnicocientífico nacional.

En ese sentido, no se manipulan ni varían intencionadamente las variables independientes, simplemente se observan los fenómenos tal y como se dan en su contexto natural, para posteriormente analizarlos. Se evalúa información sobre diver-sos conceptos (variables), aspectos, dimensiones o componentes del fenómeno a investigar, en una circunstancia tempore - espacial determinado.

\section{Resultados}

A fin de determinar cuáles son los parámetros provenientes de efluentes líquidos del Subsector Hidrocarburos que poseen mayor riesgo ambiental y a la salud de las personas, se han considerado los criterios técnicos-científicos adoptados por agencias internacionales de Europa y Estados Unidos, tales como: i) Agency for toxic Substances \& Disease Registry (ATSDR); ii) Institute for Health and Consumer Protection (IHCP); $y$, iii) United States Environmental Protection Agency (EPA), que han desarrollado estudios relacionados a los efectos de sustancias químicas y sus mecanismos de toxicidad mediante ensayos en animales de experimentación, métodos alternativos in-vitro y estudios en humanos.

A continuación, se describen las características toxicológicas de algunos parámetros considerados por las citadas agencias como los de mayor riesgo ambiental y a la salud de las personas, así como de diversas investigaciones de reconocimiento internacional, conforme se muestra en el siguiente detalle: 
Tabla 2

Efectos y características de los parámetros de contaminación ambiental, según la ATSDR 5

\begin{tabular}{|c|c|c|c|c|c|}
\hline Parámetro & $\begin{array}{l}\text { Descripción de } \\
\text { efectos nocivos a } \\
\text { la salud humana }\end{array}$ & Carcinógeno & $\begin{array}{c}\text { Efectos nocivos en } \\
\text { seres vivos }\end{array}$ & $\begin{array}{l}\text { Efectos tóxicos en } \\
\text { el ambiente (otras } \\
\text { investigaciones) }\end{array}$ & $\begin{array}{l}\text { Dosis límite } \\
\text { permisible }\end{array}$ \\
\hline Cadmio & $\begin{array}{l}\text { La mayor parte del } \\
\text { cadmio que entra } \\
\text { al cuerpo va a los } \\
\text { riñones e hígado y } \\
\text { puede permanecer } \\
\text { allí durante ańos. } \\
\text { Una pequeña } \\
\text { cantidad de cadmio } \\
\text { que entra al cuerpo } \\
\text { es eliminada } \\
\text { lentamente en la } \\
\text { orina y las heces. }\end{array}$ & Sí & $\begin{array}{l}\text { Posee } \\
\text { capacidad } \\
\text { bioacumulativa. }\end{array}$ & $\begin{array}{l}\text { Interfiere en la entrada, } \\
\text { transporte y utilización de } \\
\text { elementos esenciales (Ca, } \\
\text { Mg, P y K) y del agua, } \\
\text { provocando desequilibrios } \\
\text { nutricionales e hídricos } \\
\text { en las plantas. Las plantas } \\
\text { expuestas a suelos } \\
\text { contaminados con cadmio } \\
\text { presentan modificaciones } \\
\text { en la apertura estomática, } \\
\text { fotosíntesis y transpiración. } \\
\text { Uno de los síntomas } \\
\text { de su toxicidad es la } \\
\text { clorosis producida } \\
\text { por una deficiencia } \\
\text { en hierro, fosfatos o } \\
\text { por la reducción del } \\
\text { transporte de manganeso, } \\
\text { produciendo alteraciones } \\
\text { en la funcionalidad de } \\
\text { la membrana plasmática } \\
\text { y desequilibrios en } \\
\text { el metabolismo del } \\
\text { cloroplasto, inhibiendo } \\
\text { la síntesis de clorofila y } \\
\text { reduciendo la actividad de } \\
\text { enzimas implicadas en la } \\
\text { fijación de CO (Rodriguez } \\
\text { Serrano, Martínez De La } \\
\text { Casa, \& Romero Puertas, } \\
\text { 2008, pág. 142). }\end{array}$ & $\begin{array}{l}\text { La Administración } \\
\text { para la Salud } \\
\text { y la Seguridad } \\
\text { Ocupacional (en } \\
\text { adelante OSHA) } \\
\text { ha establecido } \\
\text { un límite de } \\
\text { exposición legal de } \\
5 \mu g / \mathrm{m}^{3} \text { de cadmio } \\
\text { como promedio } \\
\text { (jornada diaria de } \\
\text { ocho horas). }\end{array}$ \\
\hline Mercurio & 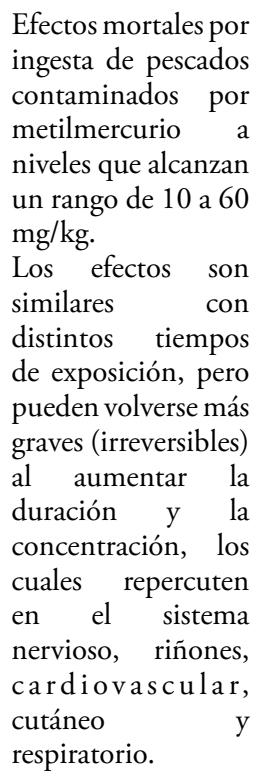 & No & $\begin{array}{l}\text { Posee capacidad } \\
\text { bioacumulativa y } \\
\text { bioconcentradora }^{6} \text {. }\end{array}$ & $\begin{array}{l}\text { En la flora empieza en la } \\
\text { raíz y afectan sucesivamente } \\
\text { el resto de las plantas; en las } \\
\text { hojas se producen graves } \\
\text { daños en los cloroplastos y } \\
\text { mitocondrias, lo que altera } \\
\text { los procesos de fotosíntesis y } \\
\text { respiración. En una fase más } \\
\text { avanzada de alteración, se } \\
\text { producen intensos cambios } \\
\text { metabólicos y de regulación } \\
\text { celular, y ocurre finalmente } \\
\text { el estímulo de la senescencia } \\
\text { por acumulación crónica } \\
\text { del metal pesado, lo que } \\
\text { puede resultar en la muerte } \\
\text { de las plantas. Es decir, la } \\
\text { capacidad bioacumulativa } \\
\text { y bioconcentradora del } \\
\text { mercurio afectaría a toda } \\
\text { la cadena trófica (Posada \& } \\
\text { Arroyave, 2006, pág. 61). }\end{array}$ & No se indica. \\
\hline
\end{tabular}

5 Es una agencia federal del Departamento de Salud y Servicios Humanos de los Estados Unidos de América de salud pública, fundada el 2 de diciembre de 1970 en Washington, cuya finalidad es prevenir las exposiciones y enfermedades relacionadas con sustancias tóxicas dańinas.

6 La bioconcentración es descrita por la USEPA (2005) como el proceso que resulta de la acumulación de un producto químico en un organismo a niveles más altos que los encontrados en su alimento. Esto ocurre cuando un compuesto químico comienza a concentrarse en un porcentaje mayor en su paso por la cadena trófica. Entonces, un consumidor de tercer orden puede acumular por medio de su comida una concentración mucho mayor que la presente en un organismo de un nivel inferior en la cadena. 


\begin{tabular}{|c|c|c|c|c|c|}
\hline Plomo & $\begin{array}{l}\text { Se han informado } \\
\text { efectos neurológicos } \\
\text { y conductuales } \\
\text { menos severos } \\
\text { en trabajadores } \\
\text { expuestos al plomo } \\
\text { que presentan } \\
\text { niveles en sangre } \\
\text { de entre } 40 \text { y } 120 \\
\mu g / d L \text { Además, } \\
\text { los efectos adversos } \\
\text { en nińos pueden } \\
\text { presentarse a niveles } \\
\text { bajos en sangre de } \\
\text { menos de } 10 \text { pg/dL, } \\
\text { y posiblemente no } \\
\text { se puedan detectar } \\
\text { mediante una } \\
\text { exploración clínica. } \\
\text { Asimismo, inhibe } \\
\text { la habilidad del } \\
\text { cuerpo para fabricar } \\
\text { hemoglobina, al } \\
\text { interferir con varios } \\
\text { pasos enzimáticos } \\
\text { de la ruta del grupo } \\
\text { hemo. }\end{array}$ & $\begin{array}{l}\text { Probables } \\
\text { carcinógenos } \\
\text { humanos. }\end{array}$ & $\begin{array}{l}\text { Posee capacidad } \\
\text { bioacumulativa y } \\
\text { bioconcentradora. }\end{array}$ & $\begin{array}{l}\text { En un suelo contaminado } \\
\text { por plomo, este puede ser } \\
\text { absorbido por las raíces de } \\
\text { las plantas, acumulándose } \\
\text { en ellas. Asimismo, el } \\
\text { plomo que se encuentra en } \\
\text { el aire suele adherirse en las } \\
\text { hojas de los vegetales. Casi } \\
\text { todo el plomo orgánico que } \\
\text { se ingiere se absorbe; sin } \\
\text { embargo, la mayor parte } \\
\text { del plomo que entra al } \\
\text { cuerpo se excreta por medio } \\
\text { de la orina o a través de la } \\
\text { evacuación biliar (en última } \\
\text { instancia a través de las } \\
\text { heces). } \\
\text { El plomo presenta efectos } \\
\text { teratogénicos (provocando } \\
\text { malformaciones) (Moreno } \\
\text { Grau, 2003, pág. 227). }\end{array}$ & $\begin{array}{l}\text { La OSHA ha } \\
\text { establecido un } \\
\text { límite de exposición } \\
\text { permisible (PEL) } \\
\text { para el plomo de } 50 \\
\mu \mathrm{g} / \mathrm{m}^{3} \text { (jornada de } \\
\text { ocho horas). }\end{array}$ \\
\hline Arsénico & $\begin{array}{l}\text { En casos fatales, se } \\
\text { describieron niveles } \\
\text { de arsénico en } \\
\text { sangre superiores } \\
\text { a } 3 \mathrm{mg} / \mathrm{l} \text {. La dosis } \\
\text { letal de trióxido de } \\
\text { arsénico ingerido } \\
\text { oscila entre } 70 \text { y } \\
180 \mathrm{mg} \text {. La muerte } \\
\text { puede sobrevenir } \\
\text { en un plazo de } 24 \\
\text { horas, aunque el } \\
\text { curso habitual es de } \\
3 \text { a } 7 \text { días. }\end{array}$ & \begin{tabular}{l}
\multicolumn{1}{c}{ Sí } \\
(pulmonares \\
y cutáneos)
\end{tabular} & $\begin{array}{l}\text { Posee capacidad } \\
\text { bioacumulativa por } \\
\text { exposición crónica. }\end{array}$ & $\begin{array}{l}\text { La acumulación del arsénico } \\
\text { es mayor en las raíces de las } \\
\text { plantas, que en las semillas } \\
\text { y frutos; y en algunos } \\
\text { casos, niveles de arsénico } \\
\text { tan bajos como de } 0,7 \text { mg } \\
\text { kg-1 pueden reducir el } \\
\text { rendimiento de los cultivos } \\
\text { en un } 50 \% \text { (Prieto García, } \\
\text { Prieto Méndez, \& Callejas } \\
\text { Hernández, 2010, pág. } 31 \text { ). } \\
\text { La OMS señala que } 1 / 10 \\
000 \text { habitantes tiene riesgo } \\
\text { de adquirir cáncer de piel } \\
\text { debido a la ingesta diaria de } \\
\text { agua con concentraciones } \\
\text { de } 0,002 \text { mg/L de arsénico. }\end{array}$ & $\begin{array}{l}\mathrm{La} \text { OSHA ha } \\
\text { establecido un } \\
\text { límite de exposición } \\
\text { promedio de } 10 \mu \mathrm{g} / \\
\mathrm{m}^{3} \text { para arsénico en } \\
\text { el aire. }\end{array}$ \\
\hline TPH & $\begin{array}{lrr}\text { La } & \text { mayoría } \\
\text { de } & \text { los } & \text { TPH } \\
\text { (principalmente } \\
\text { en forma de } \\
\text { vapor o } \text { arosol) } \\
\text { pueden } & \text { ingresar } \\
\text { al } & \text { organismo } \\
\text { mediante } & \text { la } \\
\text { inhalación y } & \text { pasar } \\
\text { rápidamente } & \text { al } \\
\text { torrente sanguíneo. }\end{array}$ & Sí & No se indica. & - & $\begin{array}{l}\text { La OSHA ha } \\
\text { establecido un } \\
\text { límite de } 500 \\
\text { ppm en el lugar de } \\
\text { trabajo (no existen } \\
\text { normas o pautas } \\
\text { federales vigentes } \\
\text { para los TPH como } \\
\text { conjunto, pero sí } \\
\text { para sus fracciones } \\
\text { y componentes). }\end{array}$ \\
\hline
\end{tabular}


Tabla 3

Efectos y caracteristicas de los parámetros de contaminación ambiental, según el IHCP

\begin{tabular}{|c|c|c|c|c|}
\hline Parámetro & $\begin{array}{l}\text { Descripción de efectos } \\
\text { nocivos a la salud } \\
\text { humana }\end{array}$ & Carcinógeno & Otros efectos nocivos & Valor límite referencial \\
\hline Cadmio & $\begin{array}{l}\text { Muy tóxico al ser inhalado. } \\
\text { Puede causar efectos } \\
\text { irreversibles en humanos. }\end{array}$ & Sí & $\begin{array}{l}\text { Muy tóxico para los organismos } \\
\text { y ambiente acuáticos. Altamente } \\
\text { peligroso para el ambiente en general. }\end{array}$ & $\begin{array}{l}\text { Reino Unido: } 25 \mathrm{ug} / \mathrm{m}^{3} \text {. } \\
\text { Madrid: } 0,2 \mathrm{mg} / \mathrm{m}^{3} .\end{array}$ \\
\hline Mercurio & Muy tóxico al ser inhalado. & No & $\begin{array}{l}\text { Muy tóxico para los organismos } \\
\text { acuáticos. Puede provocar a largo } \\
\text { plazo efectos negativos en el ambiente } \\
\text { acuático. Altamente peligroso para el } \\
\text { ambiente en general. }\end{array}$ & No indica. \\
\hline Plomo & No indica. & $\begin{array}{l}\text { Solo en } \\
\text { animales }\end{array}$ & $\begin{array}{l}\text { Se bioacumula en plantas y animales } \\
\text { (terrestres y acuáticos); sin embargo, } \\
\text { no se biomagnifica en la cadena trófica. } \\
\text { Generalmente es tóxico en plantas del } \\
\text { suelo por encima de } 1,000 \mathrm{mg} / \mathrm{kg} \text {. }\end{array}$ & Madrid: $0,15 \mathrm{mg} / \mathrm{m}^{3}$. \\
\hline Arsénico & $\begin{array}{l}\text { Muy tóxico al ser inhalado } \\
\text { e ingerido. }\end{array}$ & No indica. & $\begin{array}{l}\text { Muy tóxico para los organismos } \\
\text { y ambiente acuáticos. Altamente } \\
\text { peligroso para el ambiente en general. }\end{array}$ & No indica. \\
\hline TPH & No indica. & No indica. & No indica. & No indica. \\
\hline
\end{tabular}

Tabla 4

Efectos y características de los parámetros de contaminación ambiental, según la EPA

\begin{tabular}{|c|c|c|c|c|}
\hline Parámetro & $\begin{array}{l}\text { Descripción de efectos nocivos a } \\
\text { la salud humana }\end{array}$ & Carcinógeno & $\begin{array}{l}\text { Otros efectos } \\
\text { nocivos }\end{array}$ & Valor límite referencial \\
\hline Cadmio & $\begin{array}{l}\text { Efectos mencionados según la } \\
\text { ATSDR e IHCP. }\end{array}$ & $\begin{array}{l}\text { Probablemente } \\
\text { carcinogénico en } \\
\text { seres humanos. }\end{array}$ & $\begin{array}{l}\text { No se bioacumula ni } \\
\text { se biomagnifica. }\end{array}$ & $\begin{array}{l}\text { La exposición por encima } \\
\text { de } 0,04 \mathrm{mg} / \mathrm{L} \text { en el agua } \\
\text { potable (hasta } 10 \text { días) causa } \\
\text { efectos adversos en nińos. } \\
\text { La exposición de por vida } \\
\text { por encima de } 0,005 \mathrm{mg} / \mathrm{L} \\
\text { causa efectos adversos. }\end{array}$ \\
\hline Mercurio & $\begin{array}{l}\text { La exposición en niveles altos puede } \\
\text { ocasionar problemas neurológicos, } \\
\text { cardiacos, renales, respiratorios y al } \\
\text { sistema inmunológico. }\end{array}$ & No & $\begin{array}{l}\text { Se bioacumula en } \\
\text { peces, mariscos y } \\
\text { microorganismos } \\
\text { acuáticos en forma } \\
\text { de mercurio metílico. }\end{array}$ & $\begin{array}{l}\text { La concentración máxima } \\
\text { permisible de mercurio } \\
\text { ambiental en los lugares de } \\
\text { trabajo es de } 25 \mu \mathrm{g} / \mathrm{m}^{3} \text {. }\end{array}$ \\
\hline Plomo & $\begin{array}{l}\text { La exposición a niveles altos causa } \\
\text { daños neurológicos, auditivos, de } \\
\text { anemia, en el comportamiento y } \\
\text { crecimiento y ocasionar la muerte. }\end{array}$ & $\begin{array}{l}\text { Probablemente } \\
\text { carcinogénico en } \\
\text { seres humanos. }\end{array}$ & $\begin{array}{l}\text { Se bioacumula y } \\
\text { biomagnifica a través } \\
\text { de la cadena trófica. }\end{array}$ & $\begin{array}{l}\text { Estudios demuestran cambios } \\
\text { neuropsicológicos en niños } \\
\text { con niveles de plomo en } \\
\text { sangre de } 10 \text { ug/dL, por lo } \\
\text { que se ha establecido este } \\
\text { valor como nivel de alerta. }\end{array}$ \\
\hline Arsénico & $\begin{array}{l}\text { Exposiciones altas causan } \\
\text { descoloramiento en la piel y efectos } \\
\text { neurológicos. }\end{array}$ & $\begin{array}{l}\text { La exposición a } \\
\text { largo plazo a altos } \\
\text { niveles puede } \\
\text { ocasionar cáncer. }\end{array}$ & $\begin{array}{l}\text { No se bioacumula ni } \\
\text { se biomagnifica. }\end{array}$ & $\begin{array}{l}\text { El nivel permisible de } \\
\text { arsénico en el agua de } \\
\text { bebida es de } 10 \mathrm{ppb} \text { (nivel } \\
\text { máximo contaminante). }\end{array}$ \\
\hline TPH & No indica. & $\mathrm{Si}^{\prime 9}$. & No indica. & No indica. \\
\hline
\end{tabular}

7 Fundado en la década de los 90 (Unión Europea de consumidores) y se encarga de proporcionar apoyo científico y técnico para la concepción, desarrollo e implementación y seguimiento de políticas europeas, siendo la base de datos ESIS (Sustancias químicas europeas) tomada como referencia, ya que es un sistema de información compleja que proporciona datos sobre diversos productos químicos.

8 Es una agencia del gobierno federal de Estados Unidos de América encargada de proteger la salud humana y el ambiente (aire, agua y suelo).

9 La EPA regula ciertas fracciones y productos de los TPH o residuos que contienen TPH y algunos de sus componentes individuales; por ello, determinó que el benzo[a]antraceno, benzo[a]pireno, benzo[b]fluoranteno, benzo[k]fluoranteno, criseno, dibenzo[a,h]antraceno y indeno $[1,2,3-\mathrm{c}, \mathrm{d}]$ pireno son probables carcinógenos humanos y que el acenaftileno, antraceno, benzo[g,h,i] perileno, fluoranteno, fluoreno, fenantreno y pireno no son clasificables como carcinógenos en seres humanos. 
De lo descrito en las Tablas 2, 3 y 4, se observa que, según la ATSDR, el IHCP y la EPA, así como también de diversas investigaciones de reconocimiento internacional, del total de parámetros establecidos de efluentes líquidos de la normatividad peruana, los tres (3) primeros parámetros que podrían causar un mayor riesgo al ambiente y salud de las personas son los metales plomo, cadmio y mercurio.

Sin embargo, adicionalmente a ello, para fines de la presente investigación, se considera conveniente analizar el tiempo de vida media biológica en seres vivos, conforme se muestra a continuación en la Tabla 5 .

\section{Tabla 5}

Vida media del cadmio, mercurio, plomo, arsénico y TPH

\begin{tabular}{|c|c|c|}
\hline Parámetro & Vida media biológica ${ }^{10}$ (adultos) & Fuente \\
\hline Cadmio & En el organismo: De 30 a 40 años. & (Ramirez, 2002, pág. 57). \\
\hline \multirow{3}{*}{ Mercurio } & $\begin{array}{l}\text { Inorgánico: } \\
\text { - Mujeres: } 37 \text { días. } \\
\text { - Varones: } 48 \text { días. } \\
\text { - Sangre: de } 20 \text { a } 28 \text { días. }\end{array}$ & \multirow{3}{*}{ (Español Cano, 2001, pág. 17). } \\
\hline & Elemental: 60 días. & \\
\hline & $\begin{array}{l}\text { Metilmercurio: } 120 \text { días. } \\
\text { - Sangre: } 70 \text { días. }\end{array}$ & \\
\hline Plomo & $\begin{array}{l}\text { - Sangre: } 40 \text { días. } \\
\text { - Tejido óseo y dientes: entre } 10 \text { a } 30 \text { años }\end{array}$ & (ATSDR, Lead, 2010, pág. 21). \\
\hline Arsénico & - Arsénico inorgánico en humanos: 10 horas aprox. & $\begin{array}{l}\text { (ATSDR, Estudios de Caso en } \\
\text { Medicina Ambiental (CSEM), 2009). }\end{array}$ \\
\hline TPH & No se indica. & - \\
\hline
\end{tabular}

En tal sentido, de todo lo analizado mayor riesgo ambiental y en la salud anteriormente, se realizó la clasificación de los tres (3) parámetros que causan de las personas de acuerdo a lo que se muestra en la Tabla 6.

Tabla 6

\section{Clasificación de parámetros que causan mayor riesgo ambiental y salud de las personas}

\begin{tabular}{|c|c|l|}
\hline ID & $\begin{array}{c}\text { Parámetro } \\
\text { de mayor } \\
\text { riesgo }\end{array}$ & \multicolumn{1}{c|}{ Características } \\
\hline $\mathbf{1}^{\circ}$ & Cadmio & $\begin{array}{l}\text { Cancerígeno en animales y seres humanos, puede bioacumularse y posiblemente biomagnificarse, es } \\
\text { catalogado como altamente peligroso sobre la flora, fauna y seres humanos. También, el tiempo de } \\
\text { vida media en el organismo se encuentra en el rango de 30 a 40 ańos; además, se encuentra en la lista } \\
\text { de contaminantes más peligrosos del aire (EPA). }\end{array}$ \\
\hline $\mathbf{2}^{\circ}$ & $\mathbf{P l o m o}$ & $\begin{array}{l}\text { Posible cancerígeno en animales y humanos, posee la capacidad de bioacumularse y biomagnificarse } \\
\text { en la cadena trófica, es catalogado como peligroso sobre la flora, fauna y seres humanos (efectos } \\
\text { irreversibles y teratogénicos). Su tiempo de vida en sangre es de 40 días y en los tejidos óseos y dientes } \\
\text { es de 10 a 30 años; además, se encuentra dentro de la lista de los contaminantes más peligrosos del } \\
\text { aire (EPA). }\end{array}$ \\
\hline $\mathbf{3}^{\circ}$ & Mercurio & $\begin{array}{l}\text { No es cancerígeno, pero se bioacumula y posiblemente puede biomagnificarse. Además, es catalogado } \\
\text { como altamente peligroso sobre la flora, fauna y seres humanos. Asimismo, posee posibles efectos } \\
\text { irreversibles; su tiempo de vida media es variable, teniendo un mínimo y máximo de 20 y 120 días, } \\
\text { respectivamente; y, se encuentra en la lista de contaminantes más peligrosos del aire (EPA). }\end{array}$ \\
\hline
\end{tabular}

10 La vida media biológica (o vida media) es el tiempo que se necesita, a partir del momento en que cesa la exposición, para reducir a la mitad la cantidad presente en el organismo, el cual es valorado empleando métodos de medición como la concentración en sangre (plasma), sin embargo, éste puede modificarse, por ejemplo, con la dosis y la duración de la exposición. Es decir, la duración de la retención en un compartimento se expresa mediante la vida media biológica, que es el tiempo que tarda en reducirse al $50 \%$ la cantidad de tóxico presente en el tejido u órgano, por redistribución, translocación o eliminación del organismo”. (Sociedad Española para el Estudio de Ansiedad, 2001, pág. 33.6) “ 


\section{Discusión}

Respecto a los parámetros provenientes de efluentes líquidos del Subsector hidrocarburos más representativos desde el punto de vista tóxico y nocivo (según las agencias citadas) se observa que, de conformidad a lo señalado por la Agencia para Sustancias Tóxicas y Registro de Enfermedades (ATSDR), los parámetros que poseen propiedades cancerígenas son el cadmio, arsénico y TPH; asimismo, el cadmio, mercurio, plomo y arsénico poseen capacidad bioacumulativa, siendo que de estos cuatro (4) solo el mercurio y plomo tienen capacidad bioconcentradora en la cadena trófica. En cambio, el Instituto de Sanidad y Protección de los Consumidores (IHCP), indica que los parámetros carcinógenos son el cadmio (en humanos) y plomo (en animales); además, este último es el único calificado como bioacumulador. Cabe mencionar que, respecto del parámetro TPH no se indican características y propiedades nocivas o tóxicas. Por otro lado, la Agencia de Protección Ambiental (EPA) menciona que el arsénico es el único parámetro catalogado como carcinógeno, mientras que el cadmio y plomo como probables cancerígenos. Así también, los parámetros que poseen propiedad bioacumulativa son el mercurio y plomo; siendo que este último también se bioconcentra en la cadena trófica. Del mismo modo que la anterior agencia, para el TPH no se indican características y propiedades nocivas o tóxicas.

En la misma línea, el (Ministerio de Salud - MINSA, 2016) ha calificado, entre otros, dentro de los diez (10) contaminantes de mayor preocupación para la salud pública al plomo, mercurio y cadmio.
Finalmente, según (Ramirez, 2002) y (ATSDR, Lead, 2010), los parámetros que poseen los más altos niveles de vida media biológica son el cadmio y plomo, respectivamente. Por ello, en la presente investigación se han clasificado como los parámetros de mayor riesgo ambiental al cadmio, plomo y mercurio.

\section{Conclusiones}

Se identificaron los parámetros ambientales contemplados en la normatividad ambiental nacional vigente, referentes a los LMP para efluentes líquidos en actividades del Subsector Hidrocarburos, así como sus principales propiedades físicas, químicas y/o biológicas, estudiadas y consignadas en investigaciones de reconocimiento internacional. Estos parámetros son: $\mathrm{TPH}$, cloruro, cromo total y hexavalente, mercurio, cadmio, arsénico, fenoles y sulfuros (refinerías FCC), demanda bioquímica de oxígeno, demanda química de oxígeno, cloro residual, nitrógeno amoniacal, coliformes totales y fecales, fósforo, bario, $\mathrm{pH}$, aceites y grasas, plomo y temperatura. Del total de los parámetros establecidos en el Decreto Supremo No 037-2008-PCM se realizó la clasificación de los tres (3) primeros parámetros que puedan causar un mayor riesgo ambiental y en la salud de las personas, siendo estos: el cadmio, plomo y mercurio (en ese orden). Esta clasificación se realizó tomando como referencia criterios técnicos-científicos considerados por las agencias internacionales como la ATSDR, el IHCP y la EPA, en función de sus propiedades carcinogénicas, bioacumulativas, biomanificación, efectos tóxicos y vida media biológica. Finalmente, la capacidad bioacumula- 
tiva (Posada \& Arroyave, 2006, pág. 61) de los parámetros cadmio, plomo y mercurio en los organismos que se encuentran en el primer peldaño de la cadena trófica (a corto, mediano o largo plazo) pueden traer consecuencias negativas para el entorno biológico, en los sistemas acuosos, terrestres y seres vivos.
Por ello, la evaluación de este aspecto se consideró debido a que al afectar los componentes ambientales agua y suelos, estarían impactando directamente de manera sucesiva a los factores bióticos del ambiente, que, sumado a su concentración y tiempo de permanencia podría ocasionar efectos irreversibles.

\section{Referencias}

Agencia Nacional de Hidrocarburos ANH. (2016). La cadena del sector hidrocarburos. Colombia.

Aguinaga, S. (1996). Manual de procedimientos analíticos para aguas $y$ efluentes. Uruguay.

Arévalo Aranda, C. (2016). Influencia de la densidad de corriente y tiempo de residencia en la reducción de arsénico de efluentes artificiales mediante el proceso de Electrocoagulación. Trujillo: Universidad Nacional de Trujillo.

Arraz Gonzales, J. (2011). Suelos mineros asociados a la minería de carbón a cielo abierto en España: una revisión. Madrid: Boletín Geológico y Minero de España.

ATSDR. (1999). Resumen de Salud Pública: TPH. Estados Unidos de América: ATSDR.

ATSDR. (2009). Estudios de Caso en Medicina Ambiental (CSEM). Estados Unidos de América.

ATSDR. (2010). Lead. Estados Unidos de América: ATSDR.
Autoridad Nacional del Agua - ANA. (2016). Estrategia Nacional para el mejoramiento de la calidad de los recursos hidricos. Lima: Dirección de la Gestión de Calidad de los Recursos Hídricos.

Bedoya Pérez, J., Ardilla Arias, A., \& Reyes Calle, J. (2014). Evaluación de un humedal artificial de flujo subsuperficial en el tratamiento de las aguas residuales generadas en la Institución Universitaria Colegio Mayor de Antioquía, Colombia. Scielo, 275-283.

Cárdenas Saldaña, L. (2011). Efectos de los factores antrópicos sobre la calidad ambiental en la ciudad de Huacho. Trujillo: Universidad Nacional de Trujillo.

Cornejo Cabellos, B. (1995). Operaciones de producción depetróleo - Control del medio ambiente en ONO. Lima: Universidad Nacional de Ingeniería. Obtenido de http://cybertesis.uni.pe/bitstream/ uni/11896/1/cornejo_cb.pdf

Decreto Supremo No 037-2008-PCM. (s.f.). Limites Máximos Permisibles de efluentes líquidos industriales del Subsector Hidrocarburos. 
Lima: Presidencia de Consejo de Ministros.

Decreto Supremo $\mathrm{N}^{\circ}$ 039-2014-EM. (s.f.). Reglamento para la Protección Ambiental en las Actividades de Hidrocarburos. Lima: Ministerio de Energía y Minas.

Español Cano, S. (2001). Toxicología del mercurio. Actuaciones preventivas en sanidad laboral y ambiental. Lima.

Estrella Moreira, I., \& Guevara, P. (2011). Análisis de hidrocarburos de petróleo en agua mediante Cromatografía de Gases. Universidad de las Fuerzas Armadas ESPE, 15.

Fernández Gordón, G. (2013). Validación de los métodos de ensayo para DBO5 en aguas residuales, TPH, aceites $y$ grasas en aguas residuales y suelos. Quito: Universidad Central de Ecuador.

Jimenez Aznar, A. (2000). Determinación de los parámetros físico-químicos de calidad de las aguas. Madrid.

Landis, W., \& Ming-Ho, Y. (2003). Introduction to Environmental toxicology: Impacts of chemicals upon ecological systems (Tercera ed.). Estados Unidos de América: Lewis publishers.

López, J. (2011). Evaluación de la eficiencia de un reactor anaeróbico de flujo ascendente y manto de lodos $U A S B$ para el tratamiento de aguas residuales - escala laboratorio. Quito: Universidad San Francisco de Quito.
Ministerio de Salud - MINSA. (2016). Metales Pesados y contaminación Ambiental, Retos para la Prevención y control. Lima: Centro Nacional de Epidemiología, Prevención y Control.

Moreno Grau, D. (2003). Toxicología Ambiental: Evaluación de riesgo para la salud humana. Espańa: McGrawHill.

Orozco Barrenetxea, C., Perez Serrano, A., \& Gonzalez Delgado, M. (2004). Contaminación ambiental: una visión desde la química. Madrid: Paraninfo.

Ortiz Valbuena, M. (2016). Manejo ambiental de la disposición final de los fluidos base utilizados en la perforación de algunos pozos petroleros en Colombia. Bogotá: Fundación Universidad América.

Paumier Verlayn, M., \& Nuñez, A. (2007). Caracterización geoquímica del medio ambiente en un yacimiento petrolifero cubano. La Habana: Revista Latinoamericana de Recursos Naturales.

PETROPERÚ. (1995). Programa de Adecuación y Manejo Ambiental: Refinería La Pampilla. Lima.

Posada, M., \& Arroyave, M. (2006). Efectos del mercurio sobre algunas plantas acuáticas tropicales. Medellín: Escuela de Ingeniería de Antioquia.

Prieto García, F., Prieto Méndez, J., \& Callejas Hernández, J. (2010). Bioacumulación de arsénico en las 
etapas de desarrollo de la cebada maltera (hordeum distichon l.). México.

Programa de Desarrollo Institucional Ambiental. (1999). Manual para Inspectores: Control de Efluentes Industriales. Buenos Aires.

Ramirez, A. (2002). Toxicología del cadmio. Conceptos actuales para evaluar exposición ambiental $u$ ocupacional con indicadores biológicos. Lima: Facultad de Medicina - Universidad Nacional Mayor de San Marcos.

Rodriguez Serrano, M., Martínez De La Casa, N., \& Romero Puertas, M. (2008). Toxicidad del Cadmio en Plantas. España.

Savia Perú S.A. (2010). Estudio de Impacto Ambiental y Social del proyecto de
"Levantamiento Sísmico 2D y 3D en el Lote Z-49" aprobado mediante Resolución Directoral N ${ }^{\circ}$ 089-2010EM/DGAA. Lima: Ministerio de Energía y Minas.

Sociedad Española para el Estudio de Ansiedad. (2001). Enciclopedia de Salud y Seguridad en el Trabajo: Control de la contaminación ambiental. España.

Universidad Nacional Agraria La Molina - UNALM. (17 de marzo de 2017). Ingeniería y gestión del agua residual: reusoen agricultura $y$ otros usos. Obtenido de Foro del Día Mundial del Agua: http:// www.lamolina.edu.pe/icta/ ForoDMA17/Reuso\%20del\%20 Agua.Mg.Sc.R.Miglio.pdf 